\title{
A EDUCAÇÃO MATEMÁTICA E O ENSINO DE ÁLGEBRA NA PERSPECTIVA DE DESENVOLVIMENTO DO PENSAMENTO ALGÉBRICO
}

\author{
EDUCACIÓN MATEMÁTICA Y ENSEÑANZA DEL ÁLGEBRA DESDE LA \\ PERSPECTIVA DE DESARROLLO DEL PENSAMIENTO ALGÉRICO
}

\section{MATHEMATICAL EDUCATION AND ALGEBRA TEACHING FROM THE PERSPECTIVE OF DEVELOPING ALGEBRAIC THINKING}

\author{
Márcia Azevedo Campos \\ Universidade Estadual do Sudoeste da Bahia - UESB \\ Luiz Márcio Santos Farias \\ Universidade Federal da Bahia - UFBA
}

\section{RESUMO}

Este artigo discute o ensino de álgebra na perspectiva do desenvolvimento do pensamento algébrico, a partir de atividades do livro didático de Matemática do $6^{\circ}$. Ano em consonância com a Educação Matemática. Investigou-se como é proposto o ensino de problemas envolvendo números naturais e sua capacidade de desenvolvimento do pensamento algébrico, considerado uma forma especial de pensar, importante na construção do conhecimento matemático. Buscouse, apoiados na Teoria Antropológica do Didático, objetos ostensivos e não-ostensivos que pudessem ser evocados nessa educação algébrica. Focou-se em atividades matemáticas de estabelecimento de relações, nos processos de generalizar, modelar, operar com o desconhecido como se fosse conhecido e construir significado para a linguagem simbólica algébrica. As análises apontam que a educação algébrica pautada em atividades de resolução de problemas visando a produção de significados é um caminho para o desenvolvimento do pensamento algébrico, pelas relações e conexões que necessita estabelecer para a solucioná-los, e assim para a aprendizagem algébrica e matemática.

Palavras-chave: Educação Matemática. Ensino. Livro Didático. Resolução de Problemas. Pensamento Algébrico. 


\title{
RESUMEN
}

Este artículo analiza la enseñanza del álgebra desde la perspectiva del desarrollo del pensamiento algebraico, basado en las actividades del sexto libro de texto de Matemáticas. Año en línea con la Educación Matemática. Investigamos cómo se considera la enseñanza de problemas que involucran números naturales y su capacidad para desarrollar el pensamiento algebraico, se considera una forma especial de pensar, importante en la construcción del conocimiento matemático. Buscamos, apoyados por la Teoría Antropológica de la Didáctica, objetos ostensivos y no ostensivos que pudieran evocarse en esta educación algebraica. Se centró en actividades matemáticas de establecer relaciones, en los procesos de generalización, modelado, operación con lo desconocido como si fuera conocido y construcción de significado para el lenguaje simbólico algebraico. Los análisis señalan que la educación algebraica basada en actividades de resolución de problemas que apuntan a la producción de significados es un camino para el desarrollo del pensamiento algebraico, debido a las relaciones y conexiones que necesita establecer para resolverlos, y por lo tanto para el aprendizaje algebraico y matemático.

Palabras clave: Educación matemática. Enseñando. Libro de texto. Solución de problemas. Pensamiento algebraico.

\begin{abstract}
This article discusses the teaching of algebra from the perspective of the development of algebraic thinking, based on activities in the 6th Mathematics textbook. Year in line with Mathematics Education. We investigated how the teaching of problems involving natural numbers and their ability to develop algebraic thinking is considered, considered a special way of thinking, important in the construction of mathematical knowledge. We sought, supported by the Anthropological Theory of Didactics, ostensive and non-ostensive objects that could be evoked in this algebraic education. It focused on mathematical activities of establishing relationships, in the processes of generalizing, modeling, operating with the unknown as if it were known and building meaning for the algebraic symbolic language. The analyzes point out that algebraic education based on problem solving activities aiming at the production of meanings is a path for the development of algebraic thinking, due to the relationships and connections that it needs to establish in order to solve them, and thus for algebraic and mathematical learning.
\end{abstract}

Keywords: Mathematical Education. Teaching. Textbook. Problem solving. Algebraic Thinking.

\section{1 - Introdução}

A Educação Matemática é um espaço interdisciplinar de diálogo entre a Matemática e a Educação, o ensino e a aprendizagem. Nela situam pesquisas em Didática, sobre situações de ensino e produção de conhecimento (D’AMBRÓSIO, 1993).

\begin{tabular}{l|l} 
Revista RBBA & Revista Binacional Brasil Argentina
\end{tabular} 


\section{A EDUCAÇÃO MATEMÁTICA E O ENSINO DE ÁLGEBRA NA PERSPECTIVA DE}

DESENVOLVIMENTO DO PENSAMENTO ALGÉBRICO

A problemática deste estudo surgiu em um contexto estudado e vivenciado, a sala de aula de matemática da Educação Fundamental, sobre a aprendizagem algébrica. Apoiamo-nos no quadro teórico da Educação Matemática para investigar e buscar respostas às inquietações e questões surgidas nesse contexto. Neste quadro teórico destaca-se a Teoria Antropológica do Didático - TAD que tem se destacado nos estudos sobre a Didática da Matemática e está inserida no campo da "antropologia do conhecimento, uma antropologia cognitiva" (CHEVALLARD, 1999, p. 149), e, portanto, nos aporta na discussão sobre o ensino e a aprendizagem matemática.

A Didática da Matemática "propõe descrever e explicar os fenômenos relativos às relações entre o ensino e a aprendizagem" (ALMEIDA; LIMA, 2013, p. 82) e não necessariamente se espera modelos para solucionar problemas de aprendizagem. Para Almouloud (2017, p. 14) o propósito da Didática da Matemática, enquanto ciência da educação:

[...] é o estudo de fenômenos de ensino e de aprendizagem, mais especificamente, é o estudo de situações que visam à aquisição de conhecimentos/saberes matemáticos pelos alunos ou adultos em formação, tanto do ponto de vista das características dessas situações, bem como do tipo de aprendizagem que elas possibilitam.

Neste artigo analisamos situações de ensino propostas pelo livro didático adotado pela escola participante da pesquisa, a saber, Praticando Matemática $6^{o}$. Ano - Aldrini e Vasconcelos (2015). Estas situam na transição da aritmética à álgebra, diagnosticada como um entrave na aprendizagem algébrica, tratado como uma ruptura epistemológica por Da Rocha Falcão (2003) dado a forma abrupta que se dá a transição da aritmética à álgebra. Buscamos discuti-las e analisá-las quanto à capacidade de tornar essa passagem mais tranquila e significativa para o aluno, visando a aprendizagem.

Analisar atividades do livro didático justifica-se pela sua influência no ensino que é ministrado e sobre os saberes que são institucionalizados em sala de aula a partir dele. Este exerce um domínio e, por conseguinte, um papel fundamental na produção do conhecimento escolar, acessível a professores e alunos.

Trata-se de um recorte de uma pesquisa ${ }^{\mathrm{i}}$ maior onde elaboramos uma sequência didática e experimentamos com turmas do $6^{\circ}$. Ano do Educação Fundamental, com vistas ao desenvolvimento do pensamento algébrico. Neste estudo construímos uma sequência didática e para a sua elaboração analisamos, dentre outras, as atividades do livro didático, o que aqui trazemos à discussão.

Revista RBBA Revista Binacional Brasil Argentina 


\section{DESENVOLVIMENTO DO PENSAMENTO ALGÉBRICO}

Com o objetivo de discutir o ensino de álgebra na perspectiva do desenvolvimento do pensamento algébrico, e em consonância com o quadro teórico da TAD investigamos o que é e como é proposto o ensino de problemas envolvendo números naturais no livro didático adotado. Assim, traremos alguns desses problemas, discutindo-os quanto aos objetos algébricos, e sua significação, que podem ser evocados pelos alunos na sua resolução. Interessamo-nos em fazer uma análise das organizações matemática e didática em busca de problemas que favoreçam o desenvolvimento do pensamento algébrico.

Assumimos, a princípio, o pensamento algébrico como uma ação exclusivamente humana, cognitiva e revelada na atividade matemática através do estabelecimento de relações, nos processos de generalizar, modelar, operar com o desconhecido como se fosse conhecido e construir significado para os objetos e a linguagem simbólica algébrica.

\section{2 - As teorias da Educação Matemática e o desenvolvimento do pensamento algébrico}

Chevellard (1989; 1991; 1992; 1999), no contexto da TAD, propõe uma didática específica para resolução de situações que ocorrem no interior da Matemática (e outras disciplinas), de acordo com as necessidades do objeto de estudo. Aqui, o objeto de estudo é o desenvolvimento do pensamento algébrico que objetivamos observar no seio de atividades matemáticas de operações com números naturais em forma de problemas, descritas como tarefas e que vivem no contexto institucional do livro didático do $6^{\circ}$. Ano do Ensino Fundamental. Para suas análises, tomemos o primeiro postulado da teoria sistematizada por Bosch e Chevallard (1999) no que diz que

[...] toda prática institucional pode ser analisada de diferentes pontos de vista e de diferentes maneiras por meio de um sistema de Tarefas relativamente bem circunscritas que são realizadas no fluxo das práticas sociais $(\mathrm{BOSCH}$; CHEVALLARD, 1999, p. 5, tradução nossa).

E mobilizar o pensamento algébrico em Tarefas matemáticas são estratégias didáticas de promoção da aprendizagem e de institucionalização do saber, dentro do contexto da prática social que é a escola. A TAD não se ocupa apenas em lidar com os problemas de aprendizagem, mas vai além, discute como e onde se dá esse processo didático na atividade matemática, e em outras áreas, que culmina na aprendizagem. E proporciona "instrumentos claramente operatórios" (BOSCH; CHEVALLARD, 1999, p. 4, tradução nossa), que são resultados da 


\section{A EDUCAÇÃO MATEMÁTICA E O ENSINO DE ÁLGEBRA NA PERSPECTIVA DE}

DESENVOLVIMENTO DO PENSAMENTO ALGÉBRICO

construção de um modelo batizado de organização praxeológica, cujos componentes - tipo de Tarefa, técnica, tecnologia e teoria - descrevem toda atividade matemática. Assim, um tipo de Tarefa $(\mathrm{T})$ precisa ser resolvido por uma ou um conjunto de técnicas (t) que precisam ser testadas quanto às condições e restrições (BOSCH; CHEVALLARD, 1999) de sua existência e funcionamento que é a tecnologia $(\theta)$ da técnica. E essa tecnologia, por sua vez, precisa ser justificada e legalizada por uma teoria $(\Theta)$ válida e aceita na comunidade científica. Formouse assim dois blocos: o bloco prático, o saber fazer, formado pela Tarefa e sua técnica de resolução; e o bloco teórico formado pela tecnologia da técnica e pela teoria que a justifica. E à junção desses dois blocos Chevallard (1992) denominou Praxeologia ou Organização Praxeológica $\left(\wp^{\wp}\right)$.

A análise do livro didático permitiu identificar as praxeologias matemática e didática com seus respectivos tipos de Tarefas, técnicas, tecnologia e teoria.

Entende-se por Tarefas, a partir de Chevallard (1999), situações que evocam uma ação a ser realizada, e assim usaremos para designar as situações de ensino do livro didático analisadas em nossas discussões. Assim, tudo o que é solicitado para uma pessoa fazer e é mediado por verbos de ação será uma Tarefa ou um tipo de Tarefa, que evoca uma determinada ação.

Ilustramos com problemas encontrados no livro didático que analisamos.

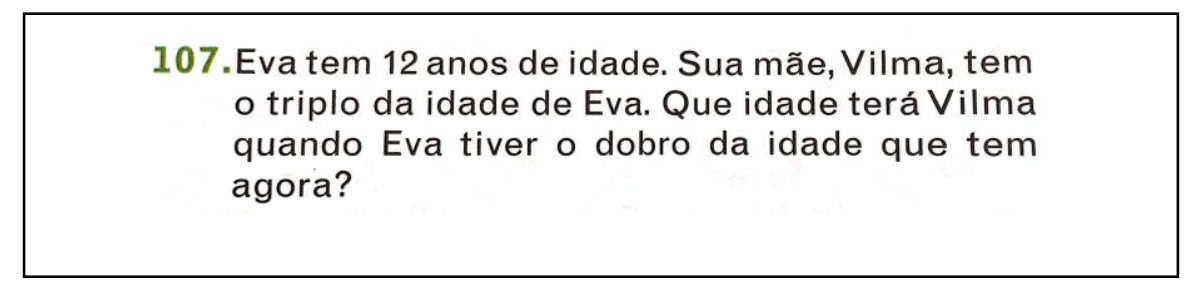

Figura 1: Problema extraído do Livro didático Praticando Matemática - $6^{\circ}$ ano Fonte: Aldrini; Vasconcelos (2015, p.76).

O problema apresentado na Figura 1 é classificado como um tipo de tarefa de estrutura aritmética e para a sua resolução requer apenas tratamentos (DUVAL, 2003) sucessivos, técnicas de manipulações, que são relações estabelecidas com os dados do problema, no entanto, mais diretas e imediatas. Quanto à sua capacidade cognitiva, pode promover o desenvolvimento do pensamento algébrico pelas relações que sugerem estabelecer, dentro da teoria operações com números naturais que a justifica, como múltiplos de um número e suas manipulações.

Revista RBBA $\mid$ Revista Binacional Brasil Argentina 

DESENVOLVIMENTO DO PENSAMENTO ALGÉBRICO

Sobre essas manipulações dos objetos matemáticos, visíveis e não visíveis, Bosch e Chevallard (1999) apresentam o termo ostensivo, usado para indicar aquilo que se apresenta visível, manipulável e estabelecem uma dialética do ostensivo e do não-ostensivo onde buscam responder a origem dos conceitos matemáticos. É a partir de objetos não-ostensivos, não visíveis como grande parte dos objetos matemáticos, e sua relação com os objetos ostensivos que os representa e os externa na escrita ou na oralidade que se dá a atividade matemática (CAMPOS; FARIAS, 2019).

Neste sentido, em nossas análises nos referiremos a objetos diretamente acessíveis, manipuláveis ou não, como definem Bosch e Chevallard (1999, p.82):

(...) os conceitos surgem da manipulação de ostensivos dentro de determinadas organizações matemáticas (...) e esta mesma prática que, ao institucionalizar ou oficializar-se, estabelece vínculos entre ostensivos e não-ostensivos que permitiram aos primeiros remeter ou representar aos segundos em futuras possíveis atividades.

A Teoria dos Registros de Representação - TRRS (DUVAL, 2003; 2009; 2011) explica tal situação de manipulação como sendo uma característica dos objetos matemáticos, pois estes só são acessíveis a partir de uma representação. Na perspectiva da TAD, os conceitos só são construídos a partir da manipulação de objetos matemáticos ostensivos. E esse pode ser um entrave cognitivo na aprendizagem matemática.

Duval (2003) afirma que as competências algébricas são estruturadas pela capacidade de produzir expressões algébricas que traduzem um problema e pelos aspectos sintáxico e semântico das expressões algébricas ao manipulá-las formalmente. Duval (2003; 2009) define tais situações como operações cognitivas de conversão e tratamento ${ }^{i i}$ presentes na atividade matemática e fundamentais para que ocorra a aprendizagem.

Tarefas como a apresentada na Figura 1 podem ser resolvidas por sucessivos tratamentos, em técnicas de tentativa e erro, operações inversas, dentre outras que podem surgir no contexto da resolução e até imprevisíveis. Entendemos que a técnica consiste em como fazer, responder ou executar uma certa Tarefa que pode fracassar em algumas conjunturas, o que é denominado de alcance da técnica. A técnica de equacionar, por exemplo, ainda não existe nesse contexto e só faria sentido se fosse compreensível e justificável pelos sujeitos que a praticam. No entanto o conteúdo equação e a técnica equacionar não faz parte das orientações curriculares, os PCN (BRASIL, 1988) que discutiremos na sequencia deste texto, para o ano analisado na pesquisa, fica subtendido nos problemas que envolvem termos desconhecidos.

Revista RBBA $\mid$ Revista Binacional Brasil Argentina 


\section{A EDUCAÇÃO MATEMÁTICA E O ENSINO DE ÁLGEBRA NA PERSPECTIVA DE}

DESENVOLVIMENTO DO PENSAMENTO ALGÉBRICO

Justificar racionalmente o uso de cada técnica é definido por Chevallard (1999) como um discurso tecnológico, ou tecnologia. Esse elemento da praxeologia vem para responder questões como: quais os fundamentos matemáticos que legitimam a estratégia tentativa e erro? Chevallard (1991) afirma que existe uma naturalidade institucionalmente aceita em praticar tal técnica, tornando sua justificativa desnecessária por essa ser a "boa maneira" de fazer. E diante da imaturidade algébrica dos alunos do $6^{\circ}$. ano é esperado que técnicas desse sentido sejam a solução para as Tarefas que lhes são propostas.

Em resumo, na perspectiva da TAD (CHEVALLARD, 1999), toda Tarefa pressupõe uma técnica para resolvê-la e pode-se recorrer a uma ou mais técnicas. Assim, tentativa e erro não seria a única técnica aceita e válida para solucionar o problema. No entanto parece ser a mais acessível por uma tecnologia capaz de compreender e validar a sua utilização, que são as operações básicas, e uma teoria que fundamenta essa tecnologia, a teoria dos Números, especificamente operações com números naturais, que é um saber do domínio desses alunos do $6^{\circ}$. Ano, tal como prevê o currículo que os assiste.

\section{3 - A educação algébrica e o ensino pautado na resolução de problemas na perspectiva de formação do pensamento algébrico}

A álgebra é vivenciada pelos estudantes desde os anos iniciais do Ensino Fundamental, ainda que a sua indicação nos documentos curriculares (BRASIL, 1988; BRASIL, 2017) seja apenas para os anos finais. No entanto, o pensamento algébrico está presente nas séries iniciais quando o aluno aprende a calcular o valor desconhecido, o valor do quadrinho tão comum nos livros didáticos, mesmo sem atribuir a esse objeto ostensivo um valor ou símbolo que o represente.

A partir do $6^{\circ}$. Ano do Ensino Fundamental, inicia-se na escola o ensino da álgebra, não formalizado pelos documentos curriculares, caracterizado pela representação dos valores desconhecidos nos problemas com o uso de letras e símbolos e pela noção de equilíbrio presente nos problemas. E então no $7^{\circ}$. Ano essa educação algébrica é formalizada ao se introduzir no currículo e nos planejamentos pedagógicos o conteúdo equação do primeiro grau e seus processos resolutivos, levando então o aluno a lidar com as incógnitas. A noção de variável e a escrita algébrica passam a ser o tema principal das aulas de matemática, a partir do $8^{\circ}$ ano. A 
Figura 2 ilustra tais situações, num paralelo entre problemas apresentados no livro didático do $6^{\circ}$ e do $7^{\circ}$. Ano.

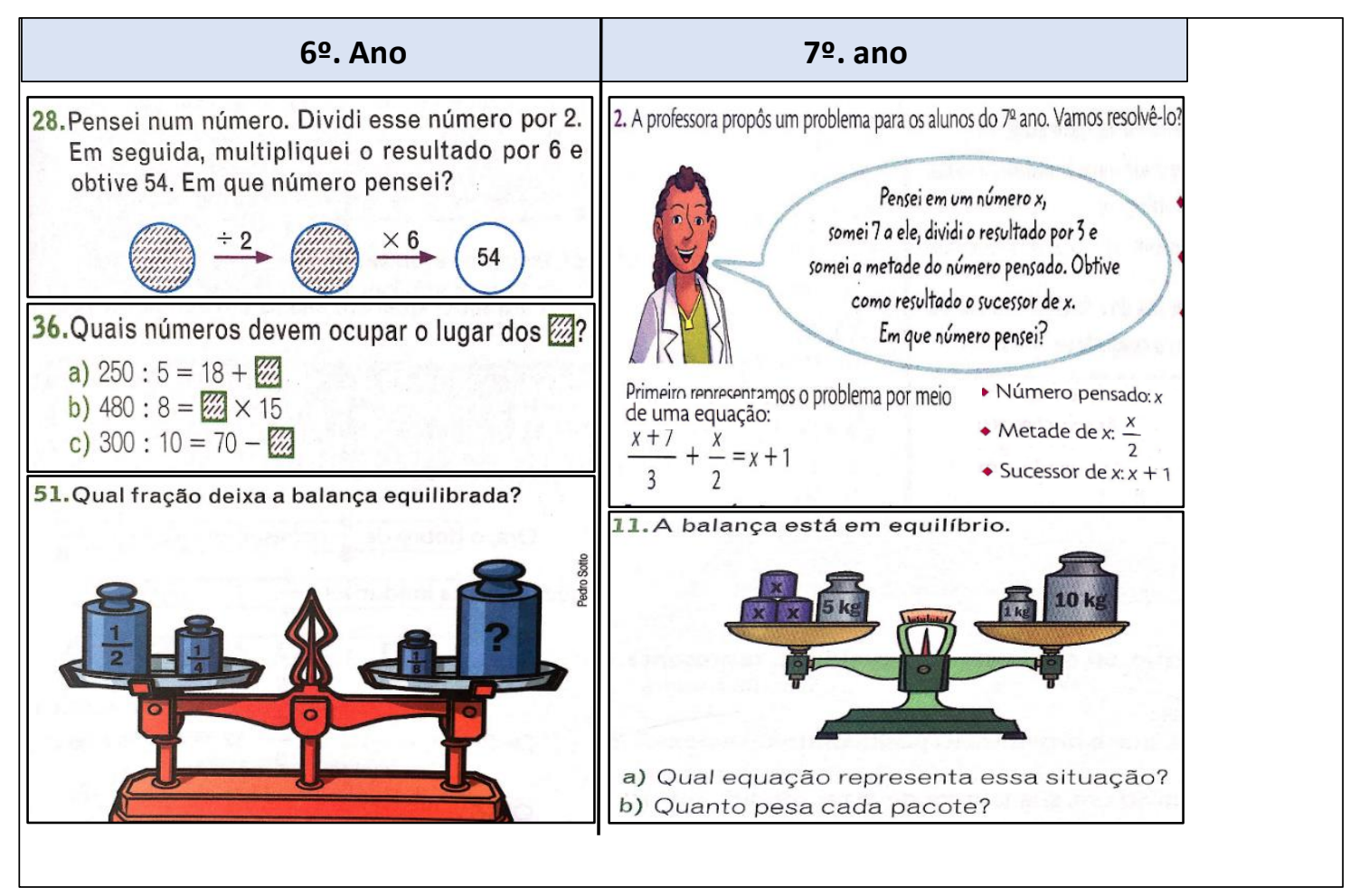

Figura 2: Problemas extraídos do livro didático Praticando Matemática Fonte: Aldrini, Vasconcelos (2015, $6^{\circ}$. Ano, p. 55, 57, 193; $7^{\circ}$. Ano, p. 207, 216)

Observa-se nos problemas ilustrados na Figura 2 que o uso de letras e o equacionar problemas institucionaliza-se nos problemas do $7^{\circ}$. Ano, que creditamos à obediência e observância das orientações curriculares. Tanto o ostensivo quadrinho como a letra $x$ tem a função de evocar um número desconhecido. No entanto, o equacionar, enquanto uma relação de equilíbrio, como a própria palavra equação, é novo no $6^{\circ}$ ano. É o limiar entre a aritmética do $6^{\circ}$. Ano e a álgebra do $7^{\circ}$. Ano do Ensino Fundamental, e onde situamos a nossa pesquisa, no vasto campo de estudo da Educação Matemática.

A matemática, com sua natureza estritamente simbólica, e a educação, com seus desafios com o ensino e a aprendizagem, imprimem às pesquisas que buscam desvendá-los um caráter muito particular a esse campo de estudo. Ao propor Tarefas que proporcionem o desenvolvimento do pensamento algébrico o quanto antes visamos amenizar possíveis dificuldades dos alunos com a aprendizagem matemática e algébrica futura. Busca-se o desenvolvimento do pensamento algébrico não necessariamente associado a conteúdos algébricos, como o uso de letras como variáveis ou incógnitas e suas manipulações, mas a partir 


\section{DESENVOLVIMENTO DO PENSAMENTO ALGÉBRICO}

de atividades matemáticas que envolvessem o pensar. E assim, com estas atividades oferecer uma possibilidade didática de promoção da aprendizagem, tal como elencamos, como premissas de pesquisa (de doutorado), as possíveis contribuições de uma sequência didática para o desenvolvimento do pensamento algébrico a partir de situações matemáticas que promovam o desenvolvimento do pensamento algébrico e sua significação.

Notadamente são elementos caracterizadores do pensamento algébrico aspectos de percepção de regularidades, a percepção de aspectos invariantes em contraste com outros que variam e a presença da generalização na expressão das relações e conexões entre as variáveis dos problemas no registro da língua natural (FIORENTINI; MIGUEL; MIORIM, 1993).

Pesquisas realizadas (CAMPOS, 2015; CAMPOS, 2019; ALMEIDA, 2016, dentre outras) com o objetivo de investigar o desenvolvimento do pensamento algébrico em estudantes da educação básica vêm mostrando a necessidade de diversificar as atividades que são propostas, sejam nos livros didáticos, sejam em outras atividades aplicadas em sala de aula. Estas pesquisas partem da premissa de que, para o desenvolvimento do pensamento algébrico, no sentido de construir significados para os objetos algébricos e suas representações, o trabalho com atividade algébrica de resolução de problemas, em detrimento ao transformismo algébrico e o uso de letras sem significa-las, é importante para que o aluno possa capturar a significação própria do objeto (como as letras), e não apenas atribuir uma lógica ou significado qualquer.

Para Radford (2009) a atividade algébrica se constitui a partir de observação de regularidades, relações e propriedades matemáticas associadas a uma metodologia considerada adequada ao desenvolvimento das capacidades algébricas, atividades estas onde os alunos deverão prever, discutir, argumentar e comprovar as suas ideias, não se prendendo unicamente com o treino de procedimentos. E este postulado de Radford foi experimentado por Campos (2019) a partir de uma sequência didática intencionalmente elaborada visando oferecer esses momentos didáticos e se mostrou bastante eficiente na educação algébrica, no desenvolvimento das capacidades algébricas, em especial, a de argumentar sobre o que foi visto, significando-o.

Na resolução de problemas há um esforço cognitivo maior do aluno, especialmente na conversão (DUVAL, 2003) da linguagem natural dos problemas para a linguagem algébrica, ação fundamental para a resolução de problemas de estrutura algébrica, e assim para o desenvolvimento do pensamento algébrico. A atividade algébrica de resolução de problemas, que têm a característica de fazer uso da linguagem natural e de contextos vivenciados pelo aluno, consolida a aprendizagem matemática pela significação dos objetos algébricos, não 


\section{DESENVOLVIMENTO DO PENSAMENTO ALGÉBRICO}

apenas como ferramentas, mas com significados (CAMPOS; FARIAS, 2019). O aluno produz significados para os conceitos, os algébricos por exemplo, dentre outras ações, quando é capaz de falar com propriedade a respeito dos objetos matemáticos da álgebra.

De forma mais ampla, a produção de significados, enquanto capacidade de argumentação do aluno sobre um determinado conteúdo, se dá a partir do momento que é capaz de produzir justificações, argumentar, ir além do que é ensinado, produzir crenças sobre o que está sendo visto e justificá-las no contexto vivido ou que possa ser vivido (CAMPOS, 2019). É pensar sobre. Nesse sentido adotamos a prerrogativa de Lins (2012) de que a produção de significados é necessária para a produção de conhecimentos, ao afirmar que "sempre que há produção de significado há produção de conhecimento e vice-versa” (p. 28).

\section{4 - Os números naturais: objeto do saber na resolução de problemas}

Na vertente do pensamento algébrico os números são tratados como objetos de estudo (LINS, 2012), deixando de servir apenas como ferramentas na resolução ou modelação de situações problemas. Neste estudo o sistema didático é constituído em torno de Tarefas articuladas dentro de uma organização matemática que envolve os números naturais, porta de entrada para o ensino da álgebra, e que propiciam a formação do pensamento algébrico. $\mathrm{O}$ objetivo é investigar as possíveis estratégias mobilizadas pelos alunos para resolver problemas com números naturais e suas implicações no desenvolvimento do pensamento algébrico.

Os números naturais possuem a característica de ser um conteúdo unificador, como a própria matemática, e faz conexões com diferentes áreas do conhecimento. Os PCN (BRASIL, 1988) preconizam que o estudo da álgebra seja introduzido no bloco de "números e operações" por meio de atividades de resolução de problemas, "ponto de partida para a atividade matemática" (p. 39-40), com o objetivo de observar regularidades e expressar generalizações.

Nesse sentido a BNCC (BRASIL, 2017) traz avanços e prioriza, desde a unidade temática Números, "o desenvolvimento de um tipo especial de pensamento - pensamento algébrico" (p. 267), que deve ser estimulado com "as ideias de regularidade, generalização de padrões e propriedades da igualdade" (p. 268). Ressalta ainda a Base que o desenvolvimento do pensamento numérico não se completa, evidentemente, apenas com objetos de estudos descritos na unidade Números (BRASIL, 2018, p. 267). E por entendermos que esse pensamento é ampliado quando se discutem situações que envolvem conteúdo das demais áreas,

Revista RBBA $\mid$ Revista Binacional Brasil Argentina 


\section{DESENVOLVIMENTO DO PENSAMENTO ALGÉBRICO}

como a álgebra, reafirmamos a nossa hipótese de desenvolvimento do pensamento algébrico a partir de problemas numéricos.

\section{5 - Análises e discussões}

Interessou-nos verificar, apoiados no estudo epistemológico e praxeológico, se os problemas propostos no livro didático, os tipos de Tarefas e as possíveis técnicas para a sua resolução favoreciam o desenvolvimento do pensamento algébrico a partir das conexões entre o pensar e o fazer do aluno. E então discutimos as ações didáticas que poderiam colaborar nesse sentido. Vejamos, com as análises que seguem.

15. Subtraindo o dobro de dois mil e vinte e sete do triplo de dois mil e quatro, obtém-se:
a) 1958
c) 3958
b) 2050
d) 10066

16. Flávia tem 7 anos de idade, e sua irmã Daniela tem o dobro de sua idade. O pai das meninas tem o dobro da idade das duas juntas. Quantos anos tem o pai de Flávia e Daniela?

17. Somando o quádruplo de 135 com o quíntuplo de 206, obtemos:
a) 1560
b) 1570
c) 1300
d) 1499

Figura 3: Problemas extraídos do Livro didático Praticando Matemática - $6^{\circ}$ ano Fonte: Aldrini; Vasconcelos (2015, p.52).

São três problemas apresentados na ilustração da Figura 3 que podem ser convertidos em uma equação algébrica, no entanto, trata-se de uma "simples codificação"iiii (DUVAL, 2003, p.19), de operações aritméticas explícitas, não favorecendo aos estudantes o desenvolvimento do pensamento algébrico. A conversão (DUVAL, 2003) é direta do registro da linguagem natural para o registro da linguagem simbólica numérica, sem estabelecer relações entre os dados do enunciado. A restrição a esses tipos de atividade - encontrar o dobro, o quádruplo, o quíntuplo - é associar à operação correspondente, como conhecimento de múltiplos de um número.

Acrescenta-se ainda a esta atividade a forma como os problemas são propostos, o que é uma constante no livro analisado. São problemas, em sua maioria, de múltiplas escolhas que, 


\section{A EDUCAÇÃO MATEMÁTICA E O ENSINO DE ÁLGEBRA NA PERSPECTIVA DE}

DESENVOLVIMENTO DO PENSAMENTO ALGÉBRICO

de certa forma conduzem, ou induzem, os alunos a uma resolução por tentativa, por descarte de possibilidades. Não são atividades das mais propícias ao desenvolvimento do raciocínio lógico de conexões, relações e de desenvolvimento do pensamento algébrico, pela forma direta com que apresenta seus dados e a resposta é previsível e capaz de ser encontrada com recursos de operações aritméticas somente, de cálculo mental inclusive, considerando, claro, que esses alunos dominam as operações fundamentais e conseguem estabelecer relações entre elas.

Nota-se assim que o registro escrito, embora dominante, não é o único registro ativado na atividade. O discurso interior, silencioso, foi indispensável na busca a solução dos problemas. Nesse sentido construímos a nossa hipótese de que a formação do pensamento matemático, muitas vezes silencioso e subjetivo, é importante para a aprendizagem matemática e pode ser ativado a partir das ações docentes que o cerca e do domínio da teoria que o legitima. E aqui particularizamos para o pensamento algébrico, como essencial à aprendizagem algébrica futura.

Especificamente os problemas apresentados na Figura 3 não constituem uma Tarefa, pelos pressupostos da $\mathrm{TAD}$, visto que não há necessidade da implementação de uma técnica para resolvê-lo. Há apenas a necessidade de significação das palavras dobro, triplo, que remetem à multiplicação, e domínio sobre esses registros semióticos, interpretando-os.

Neste sentido surgiram os questionamentos que impulsionaram a nossa pesquisa: Qual a natureza do conhecimento matemático? Qual a natureza das dificuldades apresentadas pelos alunos na aprendizagem matemática? Como evocar os objetos não perceptíveis e não manipuláveis do conhecimento, como o pensamento algébrico? Seguimos às discussões. 


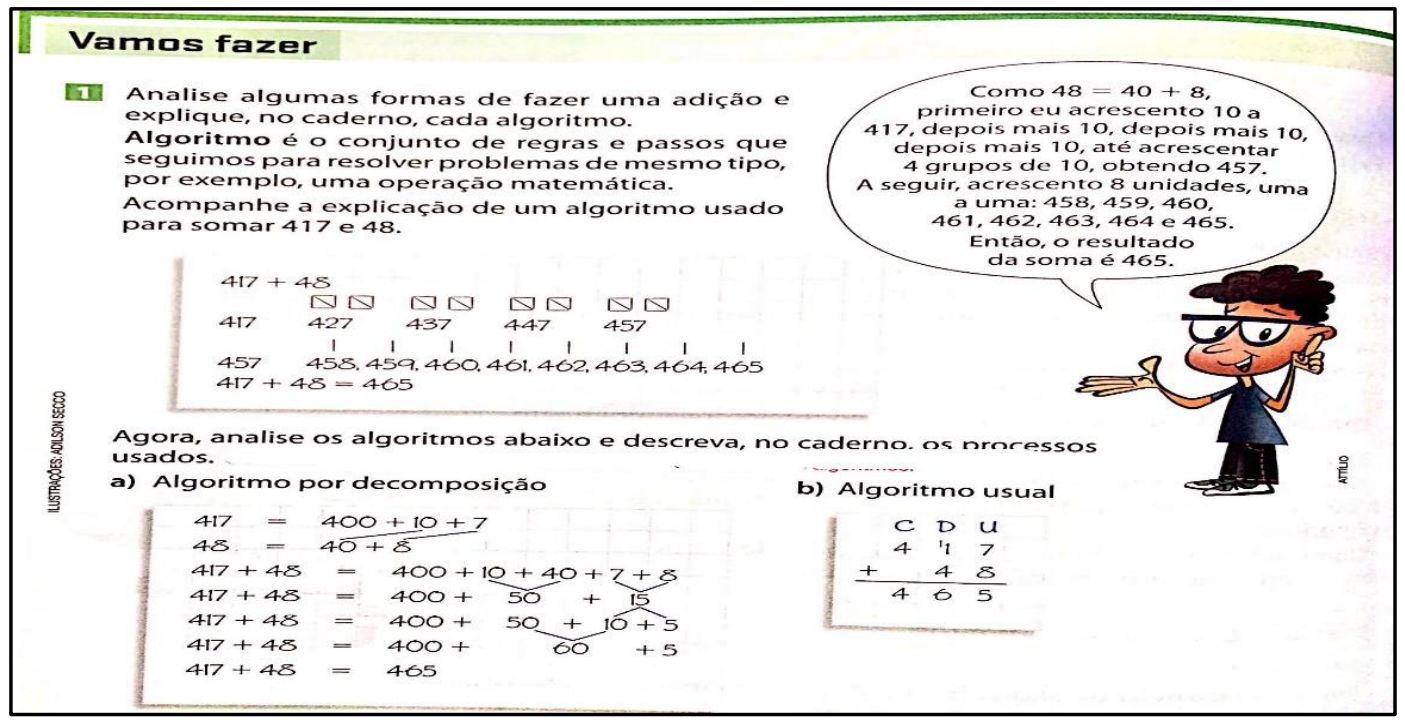

Figura 4: Problema extraído do Livro Didático Praticando Matemática - $6^{\circ}$. Ano Fonte: Aldrini; Vasconcelos (2015, p.34).

No problema exposto na Figura 4, há uso dos ostensivos risquinhos para representar as dezenas. Sugere um raciocínio de conexões com saberes já institucionalizados. No caso, existe uma condição que o aluno domine a fatoração por agrupamento e a distribuição no quadro valor do lugar do sistema de numeração decimal que é um conteúdo previsto para o $5^{\circ}$. ano e que assumimos foi visto pelo aluno.

Tal como os risquinhos, o pensamento algébrico pode surgir a partir da presença dos quadrinhos nas Tarefas representando um valor desconhecido ou uma operação necessária, como a atividade destacada na Figura 5.

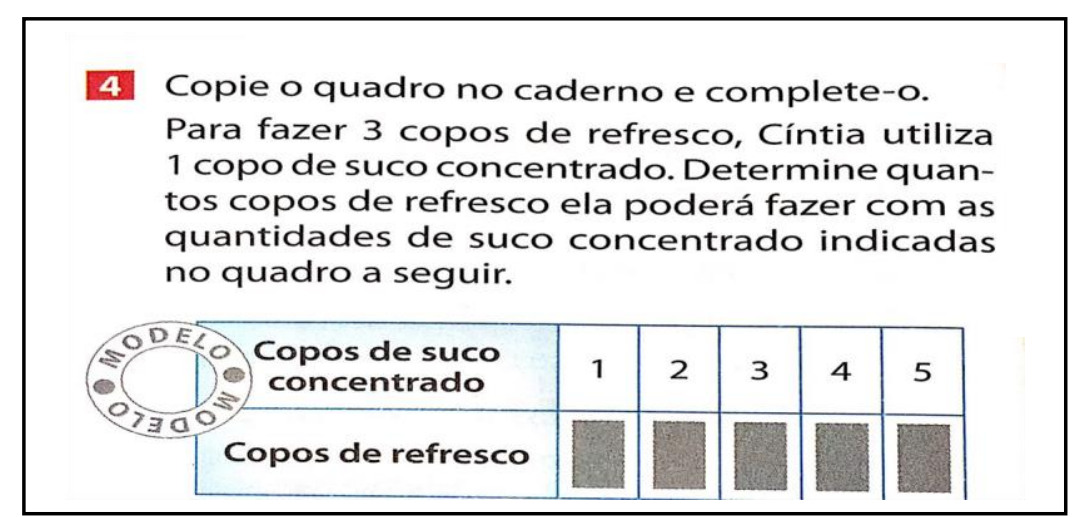

Figura 5: Problema extraído do Livro didático Praticando Matemática - $6^{\circ}$ ano Fonte: Aldrini; Vasconcelos (2015, p.54).

O ostensivo tabela (Figura 5) auxilia nas operações e relações funcionais, enquanto objetos não-ostensivos. O raciocínio funcional proveniente do raciocínio proporcional tende a 


\section{DESENVOLVIMENTO DO PENSAMENTO ALGÉBRICO}

se configurar como um alicerce da álgebra e uma base sólida para progressão das noções algébricas.

No entanto, as relações funcionais só existirão no contexto de sala de aula, na investigação diária e detectável pelo contato direto do professor com o aluno. São relações que se expressam muito mais no registro oral. Destaca-se então a importância do professor no fazer aflorar essas relações e, por conseguinte, a formação do pensamento algébrico, objeto que investigamos. Os PCN (BRASIL, 1998) propõem que o professor tenha esse papel de mediador entre o conhecimento matemático e a atividade matemática.

Bosch e Chevallard (1999) afirmam que objetos não-ostensivos só podem ser evocados a partir da manipulação adequada de objetos ostensivos associados, pois:

[...] a aplicação de uma técnica se traduz pela manipulação de ostensivos regulada por não-ostensivos. Os ostensivos constituem a parte perceptível da atividade [...]. Por contraste, a presença desse ou daquele não-ostensivo em uma prática determinada pode ser apenas induzida ou suposta a partir das manipulações de ostensivos institucionalmente associados. (BOSCH; CHEVALLARD, 1999, p. 11, destaque do autor, tradução nossa).

Bosch e Chevellard (1999) usam o termo genérico manipulação para designar os diversos usos possíveis dos objetos ostensivos pelo sujeito. Assim o objeto equação, como expressão do pensamento algébrico, que aprendemos a manipular por propriedades operatórias, é um objeto não-ostensivo que necessita de uma representação para ser evocada, no registro algébrico por exemplo. O problema apresentado na Figura 6 tem essas características.

18. Hoje, o pai de Douglas tem o dobro de sua idade. Daqui a 6 anos, Douglas terá 30 anos. O pai de Douglas tem hoje:
a) 44 anos.
c) 48 anos.
b) 46 anos.
d) 60 anos.

Figura 6: Problema extraído do livro didático Praticando Matemática $-6^{\circ}$ ano Fonte: Aldrini; Vasconcelos (2015, p.78).

No problema exposto na Figura 6 existe a possibilidade de manipular dados em busca de uma solução. Atribui-se assim significado por uma representação, no registro algébrico por exemplo, à desconhecida idade de Douglas, a partir de um ostensivo x (incógnita) e suas manipulações. 


\section{DESENVOLVIMENTO DO PENSAMENTO ALGÉBRICO}

Os objetos ostensivos na atividade matemática assumem dois papeis: a função semiótica, dada sua capacidade de produzir significado, e a função instrumental, pela sua capacidade de integrar manipulações técnicas, tecnológicas e teóricas (BOSCH; CHEVELLARD, 1999). Na análise da atividade matemática, essa dialética ostensivo/nãoostensivo (BOSCH; CHEVALLARD, 1999) é geralmente concebida em termos de signos de objetos não-ostensivos que constituem o sentido e a significação, perceptíveis por algum órgão dos sentidos. O registro (oral, da escrita, gráfico, gestual, material) é um desses objetos ostensivos pois "é o sistema no qual ocorre ou se realiza a representação de um dado objeto, externando, assim, o objeto não-ostensivo (ideia, noção, conceito) pensado pelo sujeito" (HENRIQUES; ALMOULOUD, 2016, p. 469).

Assim, conjecturamos, apoiados teoricamente no que argumentam Bosch e Chevallard (1999), que propor problemas no ensino de Matemática que admitam diferentes soluções, com base em diferentes técnicas que ativam uma pluralidade de registros ostensivos, como o oral, escrito, gráfico e gestual, é um caminho à aprendizagem. Em nosso estudo (CAMPOS, 2019) e nas pesquisas correlatas identificamos que a diversidade de ostensivos tem papel vital para a aprendizagem matemática, e é através deles que os não-ostensivos, como o pensamento algébrico e os conceitos, são construídos.

\section{6 - Considerações Finais}

O objetivo deste texto foi discutir como as escolhas das atividades do livro didático, enquanto material didático de fácil acesso ao professor, permitem controlar os comportamentos dos alunos na relação com a aprendizagem matemática algébrica. Analisamos problemas que traziam objetos ostensivos, como quadrinhos, bolinhas, tabelas, esperando um pensamento algébrico que subsidiasse as primeiras ideias dos não-ostensivos incógnita e variável, introduzisse a álgebra e a formação do pensamento algébrico.

Observou-se no livro didático uma ênfase maior nos problemas aritméticos. Em sua maioria apresenta sequências numéricas de indução ao raciocínio aritmético e não foi observado indução ao raciocínio funcional. Entendemos que há aí uma restrição imposta pelo currículo do $6^{\circ}$. Ano, o fato de não ter iniciado a educação algébrica.

Observamos em nossas análises que existe uma restrição imposta pelos documentos curriculares, que traduz em uma separação entre aritmética e álgebra no ensino de Matemática \begin{tabular}{l|l} 
Revista RBBA & Revista Binacional Brasil Argentina
\end{tabular} 

DESENVOLVIMENTO DO PENSAMENTO ALGÉBRICO

no nível fundamental, especificamente do $6^{\circ}$. para o $7^{\circ}$. Ano. Essa separação trouxe rupturas no ensino de Matemática que entendemos ser um dos fatores geradores das dificuldades de aprendizagem algébrica no $7^{\circ}$.ano, quando a álgebra é formalmente apresentada aos alunos, pela atual orientação curricular. E estudos como o nosso, que situou no $6^{\circ}$. Ano, limiar entre a aritmética e a álgebra escolar, com sua linguagem própria de símbolos e letras que se inicia no $7^{\circ}$. Ano, buscou soluções a esse entrave, tanto no campo epistemológico como cognitivo.

Consideramos o raciocínio de generalização, presente no problema exposto na Figura 5, o primeiro passo para a formação do pensamento algébrico que capacita o aluno a resolver problemas algébricos futuros. É a ampla habilidade de compreender a situação, identificar variáveis, relacionar elementos relevantes, rememorar saberes aprendidos e guardados na memória e então compará-los. Presumimos que tal habilidade, cuja origem está nas operações básicas da aritmética, é reflexo de uma capacidade algébrica, o que implica uma estreita ligação com o pensamento algébrico (BLANTON; KAPUT, 2005).

Lins e Gimenez (2001) alertam para o ensino carregado de aritmetização do raciocínio quando, acostumados ao aritmeticismo, os alunos sentem dificuldades na educação algébrica. Coincide também com o que Da Rocha Falcão (1993) tratou como ruptura epistemológica na passagem da aritmética à álgebra, que pode ser amenizada oferecendo atividades e momentos didáticos que oportunizem o desenvolvimento do pensamento algébrico.

Um ensino pautado na significação, e aqui defendemos a valorização do pensamento algébrico de resolução como um veículo à aprendizagem matemática algébrica, é uma metodologia de construção processual, gradual, autônoma e sistemática Argumenta Radford (2009) que este deve passar pelos problemas aritméticos até chegar aos problemas algébricos, pois nessa passagem processual dos não-ostensivos da aritmética para os da álgebra, reside o desenvolvimento do pensamento algébrico.

Os resultados da pesquisa maior de Campos (2019), experimentada com os problemas que aqui analisamos, dentre outros, apontam que propor atividades aritméticas e algébricas na forma de resolução de problemas é um caminho para o desenvolvimento do pensamento algébrico, pelas relações e conexões que necessita estabelecer para a solucioná-los. O uso da linguagem natural e de situações contextualizadas nos problemas matemáticos aproxima o aluno de sua realidade, do que lhe é próximo, útil e prazeroso, além de desmistificar a ideia de uma disciplina de difícil aprendizagem. 
No ensino da matemática, a possibilidade de manipular essa linguagem é o ápice do desenvolvimento do pensamento algébrico, como de qualquer conhecimento. E o domínio da linguagem pode levar o aluno a aprender o que aparentemente não sabe (RADFORD, 2009), como tratar o desconhecido como se fosse conhecido, um dos pilares do desenvolvimento do pensamento algébrico, construindo assim uma aprendizagem significativa e duradoura.

De acordo com Chevallard (1991), as relações pessoais dos estudantes com o saber são culturalmente construídas, mediadas pelas relações institucionais impostas a eles por instituições a que eles se submetem. E estas restrições vem da escola e suas diretrizes curriculares, do livro didático como manual de ensino, ou do contexto institucional onde elas vivem. O mesmo ocorre com o saber matemático. A aprendizagem das operações com números naturais parece ser natural às crianças, desde as instituições familiares e sociais da infância (BOSCH; CHEVALLARD, 1999). Mas os saberes relacionados à álgebra são impostos pela instituição escolar. Assim, para que o estudante aprenda os saberes relacionados ao pensamento algébrico, da mesma forma que os demais saberes matemáticos, será necessário que se criem condições para o estabelecimento da relação pessoal desses estudantes com esses saberes, os mesmos que permitirão a passagem da aritmética à álgebra.

Bosch e Chevallard (1999) afirmam que as dificuldades na utilização dos ostensivos de representação dos objetos matemáticos está na relação não tão direta e natural entre o sistema de leitura e a escrita, ou seja, na conversão (DUVAL, 2003). A escrita congela os objetos no papel, enquanto que o discurso oral, como o da sala de aula, os movimenta. Usar estratégias didáticas em sala de aula a partir das situações que são acessíveis a professores e alunos, como as do livro didático, com variação de linguagens, exploração de ostensivos facilmente manipuláveis e de não-ostensivos facilmente acessíveis é um requisito básico apenas para o propósito de iniciar a educação algébrica em sala de aula.

A linguagem é um importante recurso semiótico que permite a inter-relação com os demais saberes e está diretamente ligada à proposição de Tarefas em situação contextualizada, e permite a comunicação dos resultados. É, assim, fundamental na construção do saber matemático podendo contribuir de forma efetiva na passagem do raciocínio de relações aritméticas ao pensamento algébrico. E o domínio dessa linguagem matemática dos problemas é um dos pilares (RADFORD, 2009) do desenvolvimento do pensamento algébrico, como dissemos anteriormente, e um dos principais objetivos do ensino da matemática. 


\section{DESENVOLVIMENTO DO PENSAMENTO ALGÉBRICO}

Conforme argumentam Campos e Farias (2019) ao inserir nesta discussão não estamos acrescentando ou transferindo responsabilidades ao professor, às instituições ou aos órgãos regulamentadores, nem tampouco propondo modelos de ensino a seguir. Não o seria até porque também entendemos que modelos são falíveis, não se encaixam nos contextos específicos de cada aluno, estes generalizam e ainda uniformizam as pessoas. Propomos sim estratégias didáticas e de resolução de problemas que amenizem as rupturas da passagem da aritmética à álgebra, que possibilite o desenvolvimento do pensamento algébrico e então promova o conhecimento.

\section{7 - Referências}

ALDRINI, A.; VASCONCELOS, M. J. Praticando Matemática. 6 ${ }^{\circ}$. Ano. Editora do Brasil: São Paulo, 2015.

ALMEIDA, F. E. L; LIMA, A. P. B. Negociações do Contrato Didático na Passagem da Linguagem Natural para a Linguagem Algébrica e na Resolução da Equação no $8^{\circ}$ Ano do Ensino Fundamental. Zetetiké, FE/Unicamp, v. 21, n. 39, 2013.

ALMEIDA, J. R. Níveis de desenvolvimento do pensamento algébrico: um modelo para os problemas de partilha de quantidade. 2016.Tese (Doutorado em Educação Matemática e Tecnológica). Universidade Federal de Pernambuco, Recife.

ALMOULOUD, S. Fundamentos norteadores das teorias da Educação Matemática: perspectivas e diversidade. Amazônia - Revista de Educação em Ciências e Matemática, Pará, v.13, n. 27, p. 05-35, 2017.

BLANTON, M.; KAPUT, J. Characterizing a classroom practice that promotes algebraic reasoning. Journal for Research in Mathematics Education, v. 5, n. 36, p. 412-446, 2005.

BOSCH, M.; CHEVALLARD, Y. La sensibilité de l'activité mathématique aux ostensifs objet d'etude et problematique. Recherche en Didactique des Mathématiques, v. 19, n. 1, 1999, p. 77-124.

BRASIL. Ministério da Educação. Secretaria de Educação Fundamental. Parâmetros Curriculares Nacionais (5a a 8a Séries) matemática. Brasília, DF, 1998.

Ministério da Educação. Secretaria de Educação Fundamental. Base Nacional Revista RBBA $\mid$ Revista Binacional Brasil Argentina 

DESENVOLVIMENTO DO PENSAMENTO ALGÉBRICO

Curricular Comum para o Ensino Fundamental (versão final). Brasília: 2017.

CAMPOS, M. A. Construindo significados para o x do problema. 2015. Dissertação (Mestrado em Educação Matemática) - Universidade Estadual de Santa Cruz, Ilhéus.

Uma sequência didática para o desenvolvimento do pensamento algébrico no $6^{\circ}$. Ano do ensino fundamental. 2019. Tese. (Doutorado em Ensino, Filosofia e História das Ciências) - Universidade Federal da Bahia, Salvador.

CAMPOS, M. A; FARIAS, L. M. S. A educação algébrica e a resolução de problemas numéricos no $6^{\circ}$. ano do ensino fundamental: prelúdio ao pensamento algébrico. Educação Matemática Pesquisa, São Paulo, v. 21, n. 3, p. 143-166, 2019.

CHEVALLARD, Y. Le concept de rapport au savoir. Rapport personel, rapport institutionnel, rapport officiel. Seminaire de Grenoble. IREM d'Aix-Marseille: 1989.

La Transposicion Didactica: Del saber sabio al saber enseñado. Argentina: La Pensée Sauvage, 1991.

. Concepts fondamentaux de la didactique: perspectives apportées par une approche anthropologique. Recherches en Didactique des Mathématiques, v. 12, n. 1, p. 73-112, 1992.

. L'analyse des pratiques enseignantes en théorie anthropologique du didactique. Recherche en Didactique des Mathématiques, v. 19, n. 2, 1999, p. 221-266.

D’AMBrosio, U. Etnomatemática: um programa. Educação Matemática em Revista: SBEM, São Paulo, ano 1, n.1, p. 5-11, 1993.

DA ROCHA FALCÃO, J. T. A álgebra como ferramenta de representação e resolução de problemas. In; SCHILLIEMAN, A. D. et al. (Org.). Estudos em Psicologia da Educação Matemática. Recife: Ed. Universitária da UFPE, 1993.

DUVAL, R. Registros de representações semióticas e funcionamento cognitivo da compreensão matemática. In: MACHADO, S. D. A. (Org.) Aprendizagem em matemática: registros de representação semiótica. Campinas: Papirus, 2003, p.11-33.

Semiósis e pensamento humano: Registros semióticos e aprendizagens intelectuais (Fascículo I). Tradução de Lênio Fernandes Levy e Marisa Rosâni Abreu da Silveira. São Paulo: Livraria da Física, 2009. 
- Ver e ensinar a matemática de outra forma: entrar no modo matemático de pensar os registros de representações semióticas. Organização Tânia M. M. Campos. Tradução Marlene Alves Dias. São Paulo: PROEM, 2011.

FIORENTINI, D.; MIORIM, M. A.; MIGUEL, A. Contribuição para um repensar... a Educação Algébrica Elementar. Pro-Posições, Campinas, v. 4, n. 1, p. 78-91, 1993.

HENRIQUES, A.; ALMOULOUD, S. A. Teoria dos registros de representação semiótica em pesquisas na Educação Matemática no Ensino Superior: uma análise de superfícies e funções de duas variáveis com intervenção do software Maple. Ciência e Educação. v. 22, n. 2, p. 465487, 2016.

LINS, R. C. O Modelo dos Campos Semânticos: estabelecimentos e notas de teorizações. In: ANGELO, C. L. et. al. (Ogs) Modelo dos Campos Semânticos e Educação Matemática. São Paulo: Midiograf, 2012.

RADFORD, L. Signs, gestures, meanings: Algebraic thinking from a cultural semiotic perspective. In: SIXTH CONGRESS OF THE EUROPEAN SOCIETY FOR RESEARCH IN MATHEMATICS EDUCATION. Anais... Lyon - França, 2009.

\section{SOBRE OS AUTORES}

Márcia Azevedo Campos é Doutora em Ensino, Filosofia e História das Ciências pela Universidade Federal da Bahia; Mestre em Educação Matemática pela Universidade Estadual de Santa Cruz; e licenciada em Matemática pela Universidade Estadual do Sudoeste da Bahia. Professora da Educação Básica - SEC/Bahia, do Ensino Superior na Faculdade Independente do Nordeste - FAINOR e é Analista Universitária - UESB. Organizou livros na área da Didática da Matemática e é autora de capítulos de livros publicados na área da Educação Matemática. Pesquisadora membro dos Grupos de Estudos NIPEDICMT - Núcleo Interdisciplinar de Pesquisa, Ensino e Didática das Ciências, Matemática e Tecnologias/UFBA e NeuroMATH - Grupo de Estudos e Pesquisa em Educação Matemática/IFS e Líder do NIELEM - Núcleo Interdisciplinar de Estudos da Linguagem e da Educação Matemática.

Endereço Eletrônico: azevedoxu@gmail.com

Orcid: https://orcid.org/0000-0001-8255-758X 
Luiz Marcio Santos Farias é doutor em Didática das Ciências e Matemática pela U. Montpellier 2 (França) e mestre em Didática pela U. Joseph Fourier (França). Coordena Bacharelado e é professor do Instituto de Humanidades, Artes e Ciências (IHAC); Professor da Faculdade de Educação da UFBA; do Programa de PósGraduação em Ensino, Filosofia e História das Ciências da UFBA/UEFS. Pesquisador na área de Didática das Ciências, com ênfase em Formação de professores e livros publicados na área. Orienta doutorado em co-tutela com pesquisadores das Universidades Grenoble, Sherbook, Mali, Moçambique, Aix-Marseille e Montpellier. Membro do Observatoire international de la pensée algébriqueOIPA; da Association pour la Recherche en Didactique des Mathématiques (ARDM) e da Associação Brasileira de Pesquisadores Negros (ABPN). Líder do Núcleo Interdisciplinar de Pesquisa, Ensino e Didática das Ciências, Matemática e Tecnologias - NIPEDICMT.

Endereço Eletrônico: lmsf@ufba.br

Orcid: https://orcid.org/0000-0002-2374-3873

\section{Notas}

\footnotetext{
${ }^{i}$ Referimo-nos ao estudo de doutorado de Campos (2019) realizado entre 2015-2019, que culminou na Tese cujo recorte produzimos este artigo. O parecer final do $\operatorname{CEP}\left(\mathrm{n}^{\circ} .2 .121 .524\right.$, de 14/07/2017) foi favorável à pesquisa (APROVADA) que envolveu alunos e professora de três turmas de $6^{\circ}$. Ano do Ensino Fundamental participantes. ${ }^{\text {ii }}$ Sobre tais operações cognitivas ver mais em DUVAL, R Semiosis y pensamiento humano: registros semióticos y aprendizajes intelectuales. Santiago de Cali: Peter Lang, 2004.

iii Segundo Duval (2011) os códigos são sistemas transmissores ou conversores de caráter físico da transmissão de informação. Difere dos registros que são sistemas produtores de representações, e que se referem aos objetos.
}

Recebido em: $15 / 04 / 2020$

Aprovado em: 23/05/2020

Publicado em: 01/07/2020 